\title{
Threshold concepts and core competences in the library and information science (LIS) domain: Methodologies for discovery
}

Virginia M. Tucker

\begin{abstract}
Researchers have used a variety of methodologies for investigating threshold concepts, and this paper considers these approaches for library and information science (LIS) domains. The focus is on specific benefits of constructivist grounded theory for eliciting evidence of core knowledge. Elements of research design for this purpose are discussed, including the importance of collecting experiences from the learners themselves as well as effective protocols for data gathering and analysis through the use of active tasks and semi-structured interviews. The discussion extends to implications of the research design for how it may be applied to thematic analysis more broadly, and to discovery of critical knowledge that does not have the characteristics of threshold concepts but which may indicate attributes of core competences in the LIS discipline.
\end{abstract}

\section{Introduction}

This article reports on qualitative methodologies for investigating threshold concepts within the library and information science (LIS) domain, discussing the merits and issues of each, with a focus on grounded theory for eliciting evidence of learner experiences with core knowledge. The methods covered and recommendations put forth are further considered for their application to discovering core knowledge that is important to a discipline but which does not have the characteristics of threshold concepts; in these instances, such knowledge may benefit the framing of competency-based or program learning objectives. This potential is discussed for researching critical areas in LIS study programs and for evaluating the achievement of extant competency schemas (ALA, 2009; ACRL, 2015). For the latter discussion, the theoretical underpinnings of the threshold concept framework (Meyer and Land, 2003) are informed by relevant epistemological perspectives from competency theory as viewed within higher education.

\section{Author}

Virginia Tucker, MLS, PhD, is assistant professor at the School of Information, San José State University. Her research and teaching are focused on information retrieval design, advanced search, and information architecture.

Email: virginia.tucker@sjsu.edu

Received 20 February 2017

Accepted 8 May 2017 
In the methodological discussion, specific elements of qualitative research design for the discovery of themes in the data, supported by the grounded theory case illustration, are described and recommendations are put forth. This extends to effective sampling and protocols for data gathering, semi-structured interviews, active task capturing, think-aloud, and thematic coding. The discussion extends to implications of the research design recommendations for discovery of critical knowledge that may not have the characteristics of threshold concepts but which may indicate core knowledge and competencies within the LIS discipline.

\section{Conceptual frameworks}

The fundamental theoretical framework for this research and methodological focus is threshold concepts (Meyer and Land, 2003). Interest in threshold concept theory among LIS researchers and educators began in the areas of search expertise (Tucker, 2012) and information literacy (Blackmore, 2010; Townsend, Brunetti, and Hofer, 2011; Soules, 2012); it has had continuing influence on LIS education (Tucker, Weedman, Bruce, and Edwards, 2014), particularly in information literacy (IL) with the adoption of new 'frames' for IL in higher education in 2016 (ACRL, 2016).

The secondary underlying set of conceptual principles that informs this article comes from competency theory in the context of professional and higher education (Lozano et al., 2012; Mulder, 2015). This benefits the discussion in that we explore critical knowledge that does not have the characteristics of threshold concepts, but which is considered to be essential professional knowledge, commonly expressed in the form of 'core competences' or program learning objectives. (It should be noted that 'competences' may be referred to as 'competencies' in literature and in practice. The two terms are treated synonymously here.) Although sets of competences are present in LIS professions and sub-specialities (MLA 2016; AALL 2010), as well as governmental bodies being involved in standards and competences for higher education and professions (EC, 2015; U.S. Department of Education, n.d.; UNESCO, n.d.), competency theory as a conceptual framework has had limited application to library and information studies (Gross, 2005). Indeed, it may merit further exploration in this dualistic positioning with threshold concepts for furthering understanding of how LIS competences are both determined and assessed.

\subsection{Threshold concept theory}

Threshold concept theory is a framework of characteristics for learning portals within a subject area or discipline. The theory defines a learning portal as representing "a transformed way of understanding, or interpreting, or viewing something that opens up previously inaccessible ways of thinking" (Meyer and Land, 2003, 1). And, because these "new ways of thinking cannot be accessed until the student has moved through the portal, a threshold concept is an obstacle for the learner who is unable to pass through it" (Tucker et al., 2014, 152). The learner's mastery of a threshold concept "involves learning to see some aspect of the world in a totally new, transformative, and often counter-intuitive manner. Following such transformed understanding, continued and profound learning associated with the concept becomes possible" (150). 
Educators and researchers from a wide range of academic and professional domains have responded to the theoretical framework (Flanagan, 2017). Perkins has explained, "Teachers struggle to decide what will prove most meaningful and useful. Through their notion of threshold concepts, Meyer and Land (2003) offer an insightful perspective and powerful heuristic technique for looking at this puzzle" $(2006,43)$. Researcher and educator discourse about threshold concepts has "provoke[d] reflection on the structure of disciplinary knowledge and inspire[d] investigations of learners' typical hang-ups and ways to help" (Perkins, 2010, xliii).

A threshold concept has five original characteristics: it is transformative, troublesome, irreversible, integrative, and bounded.

Transformative: causing a shift in perception and identity. Once fully understood, a threshold concept causes a dramatic shift in the learner's understanding and, with this new understanding, a consequent level of identity shift. "New understandings are assimilated into our biography, becoming part of who we are, how we see, and how we feel" (Cousin, 2010, 2).

Troublesome: initially counter-intuitive or uncomfortable. A threshold concept is difficult, counterintuitive, and/or uncomfortable to grasp. "Threshold knowledge is troublesome because it entails letting go of a prevailing understanding or even a prior ontological stance [or] subjectivity" (Tucker et al., 2014, 154).

Troublesomeness itself is "an instigative or provocative feature which unsettles prior understanding, rendering it fluid and provoking a state of liminality" (Land et al., 2010, xi). Troublesomeness has been explored in other learning frameworks as a signal of critical knowledge and transformative learning experiences (Mezirow, 2003). The Decoding the Disciplines research project also focused on this characteristic and is discussed below.

Irreversible: unlikely to be forgotten or unlearned. This characteristic has been likened to the adage 'It's like riding a bike'; once fully understood, it is unlikely to be unlearned or forgotten.

Integrative: exposing something previously hidden or where the connectedness was not understood. In learning a threshold concept, the learner is "not grasping a set of separate tools, but working with them as integrated knowledge" (Tucker $e t$ al., 2014, 154). In accommodating new knowledge, the learner must unify it with other concepts in his/her understanding. This characteristic is usually present "in varying degrees" (Land et al., 2008, x).

Bounded: having 'terminal frontiers' that border other thresholds into new conceptual areas. Boundedness helps to define borders between conceptual areas and can also "indicate the limits of a conceptual area or the discipline itself" (Boustedt et al., 2007, 504). The bounded characteristic is considered to be present less often than the other four characteristics (Meyer and Land, 2003, 6).

A threshold concept also has attributes beyond these five original characteristics, explored as the theoretical framework has evolved: reconstitutive features, ontological and epistemic shift characteristics (associated with the transformative characteristic), and changes in learner discourse. Land et al. elaborate on these attributes: 
Within the liminal state an integration of new knowledge occurs which requires a reconfiguring of the learner's prior conceptual schema and a letting go or discarding of any earlier conceptual stance. This reconfiguration occasions an ontological and an epistemic shift. The integration/reconfiguration and accompanying ontological/epistemic shift can be seen as reconstitutive features of the threshold concept.

(Land, Meyer, and Baillie, 2010, xi).

Ontological shift and the attribute of ambiguity in the transformative learning experience demonstrate the clear connections between threshold concept theory and studies of liminal experiences in anthropology (Turner, 1969). Crossing a learning threshold will also evidence an enhanced and extended use of the language of the discipline. Meyer and Land have reflected that "it is hard to imagine any shift in perspective that is not simultaneously accompanied by (or occasioned through) an extension of the student's use of language" $(2005,374)$.

\subsection{Competency theory}

As a secondary framework for consideration in this article, competency theory is included in light of what it may bring to understanding core knowledge in library and information science that does not have the characteristics of threshold concepts. Such core knowledge is essential to full understanding and functioning in a professional domain and yet it may not be transformative or even troublesome to learn. Coverage of competency theory here is limited to how it may inform the discussion of discovering critical knowledge and disciplinary practices in higher education that do not have the characteristics of threshold concepts, but which are considered to be essential professional knowledge.

Mulder (2015) has written about several approaches to studying professional competence, and his insights from the situated professionalism approach are particularly apt for library and information science domains. He emphasised "the idea that the work context takes shape as a community of practice in which players interact and share and negotiate meaning" (2). Interesting, too, is his inclusion of what are often referred to as 'soft skills' in today's marketplace, referencing Bartram's 2005 generic competence framework of skills, such as supporting others, cooperating, and relating to others in a confident manner. Lozano et al. (2012) similarly examined two approaches to formulating competencies for purposes of curriculum design: concept- versus capabilitydriven. In discussing implications of the capabilities approach, they argued that "it offers a more integral, holistic, and transformative approach to higher education curricula design" (143).

In writing about the challenges of and methods for assessing competencies in higher education, Braun and Mishra (2016) first considered the most fitting definition for 'competences,' settling on: "skills that prove to be applicable in a wide range of situations and settings, that is, competences which graduates need not only in the labor market, but also those which enable them to master complex situations and adapt to new situations" (50). They studied both cognitive (discipline-specific) and non-cognitive competences, those that would again be termed as 'soft skills', such as social and communication abilities. 


\section{Methodologies and approaches}

In this methodology review, methods and sets of strategies for researching threshold concepts are presented. Primary attention is given to qualitative approaches with specific elements of research design to support the discovery of themes in the data, with emphasis on the data being from the learners' own experiences. A constructivist grounded theory case example is used to illustrate steps in threshold concepts research, and recommendations are put forth based on this study that include effective sampling and protocols for data gathering, semistructured interviews, active task capturing, think-aloud, and thematic coding and analysis stages. The discussion concludes with implications of the research design recommendations for how they may be applied to discovering critical knowledge that does not have the characteristics of threshold concepts but which may indicate attributes of core knowledge and competencies within the LIS discipline.

\subsection{Overview}

Erik Meyer and Ray Land, originators of threshold concept theory (2003), knew early on that methodologies would be critical to the continuing evolution and furtherance of the theory:

To move forward in our understanding of the acquisition of threshold concepts, from both teachers' and students' perspectives, we need to devise methods of observation and enquiry that allow us to explore variation in students' experiences of threshold concepts in rather special ways

(Meyer and Land, 2005, 384).

As described above, although the theoretical framework is now just a decade and half old, it has garnered interest from a broad range of academic disciplines and, with this growth, the methodological approaches enlisted have become more diverse as well (Davies and Mangan, 2005; Tight, 2014). This overview presents several of the methods being used, with approaches of particular interest covered in more detail.

Critics of threshold concepts as a theoretical framework have in fact focused on the methodological challenges of researching them. Quinlan et al. (2013) stated that attempts to identify, rather than to explore, threshold concepts through a mismatch of methodology is at the root of problematic research designs. Other detractors have expressed concerns over the lack of definition in the characteristics of threshold concepts, with Rowbottom (2007) being an early and articulate framer of the difficulties that any "empirical exploration of threshold concepts is liable to encounter" (268). He also expressed concerns over assessment of threshold learning, juxtapositioning the nature of concepts versus abilities, and posing several acute questions that researchers and curriculum developers are still working to address, including the most basic, "how it is possible to test for concepts, rather than abilities?" (263).

Although it is true that "the ongoing effort to study threshold knowledge is itself a study in troublesomeness" (Tucker et al., 2016, 27), the range of methods being used includes several that are noteworthy. Barradell and Peseta (2016) studied transactional curriculum inquiry as a method, and Barradell had earlier provided 
an overview of consensus methods for researching threshold concepts (2013). Quinlan et al. (2013) reviewed six research protocols, and Walker (2013) utilised mixed methods that included aspects of objectivist grounded theory. The recently adopted ACRL framework for information literacy (IL) in higher education was based on research that used the Delphi method (Townsend et al., 2016). In the study, data were elicited from educators, LIS faculty and/or librarians who teach IL, and six threshold concepts were arrived at through iterative Delphi stages of sharing outcome summaries from the participants, resulting in a set of "frames". This included concepts such as "Information has value" and "Scholarship as conversation" (ACRL, 2016). However, as discovered in the Decoding the Disciplines studies, discussed below, and noted by Shinners-Kennedy, conclusions based on instructor views are inherently incomplete. He specifically cites problematic outcomes from Delphi process studies, noting that instructors/tutors tend to be guided by "foundations of the discipline [that are] embodied in the concepts identified as core or fundamental. The tutor then falls victim to expert blind spot" $(2016,259)$.

Zwaneveld et al. (2016) analysed methods used to study threshold concepts in computer science, with particular attention to how much overlap existed between concepts identified by students as being threshold concepts and those identified by their teachers, including analysis at the level for which each of the five main characteristics the participants deemed to be present. More recently, vignettes have been used as a strategy for studying threshold concepts and as a way to elicit narratives from students about their understandings - and perceptions of valueof the concepts in the ACRL Framework (Benedetti, Jackson, and Luo, 2017).

One of the more widely used methods for exploring threshold concepts has been phenomenography and variation theory (Åkerlind, McKenzie, and Lupton, 2014). This approach uses differentiation to enable learners to become more discerning and thereby capable of handling new or challenging situations. "Learning is thus seen as occurring through a shift in awareness, where a student becomes aware of aspects of a concept that they had not previously noticed" (Yukawa, 2015, 162).

\subsection{Decoding the disciplines}

A research front that developed in parallel to threshold concept theory is the Decoding the Disciplines project at Indiana University. These two research families grew in awareness of each other in the late 2000s and, in 2012, held collaborative workshops at the 4th Biennial Threshold Concepts Conference at Trinity College in Dublin. The Decoding researchers had developed a seven-step model intended to help educators identify essential concepts in their disciplines and, from this, to develop robust instructional and assessment materials (Pace and Middendorf, 2004). The model is based on investigating 'bottlenecks' in student learning experiences that indicate troublesome knowledge (Díaz and Pace, 2012).

The Decoding project began as the History Learning Project at Indiana University and has been applied to subjects including astronomy, biology, and physiology (Pace and Middendorf, 2004; Glenn, 2009). Identifying the bottlenecks is done by researchers interviewing faculty to determine which concepts their students find most troublesome. This is used as a "starting point for studies that not only 
explore what must be explicitly taught to increase learning [in history courses] but also what the faculty perception of bottlenecks to learning tells us about the students themselves" (Díaz et al., 2008, 1212). The objective of the Decoding project is to support students in "learning the modes of thought of a new discipline" (Burkholder, 2011, 110). The parallels between the Decoding the Disciplines model's bottlenecks and the troublesomeness of threshold concepts are clear, but a primary difference is that threshold concepts have characteristics in addition to troublesomeness. Díaz and Pace view the model as contributing to threshold concept research for its methodological processes that can deconstruct tacit disciplinary knowledge (2012).

\subsection{Grounded theory}

Grounded theory (GT) has been characterised as being more a set of qualitative research strategies than a methodology unto itself (Bawden, 2012) and an "integrated and iterative approach to collection and analysis of information in any kind of qualitative research" (ibid., 156). With this view, a grasp of its strategies may then be useful to other qualitative methods involving thematic analysis. In addition, it must be stated at the start of this discussion of grounded theory that it is framed with the assumption that the positioning and timing of the literature review for relevant theoretical and conceptual frameworks has been established. The literature review, and when it takes place during grounded theory research, is an ongoing and nuanced debate. In fact, one of the thornier aspects of grounded theory - when to conduct the literature review-allows the discussion to focus on elements in the research design that involve the emergence of themes from the data. And, as stated by Jacobs, "It can be argued that the grounded analysis end of the continuum is never completely grounded, as the researcher is never innocent in the data production process, having designed the research process in a particular way" $(2014,75)$. Others have agreed that it is not practical for grounded theory researchers to wholly "jettison all their prior knowledge of the field" (Dunne, 2011, 117).

There are three main approaches to grounded theory: Glaser and Strauss (1967) originated the methodology as a "revolt against the dominance of a quantitative ideology pervading social science research during the 1960s" (Dunne, 2011, 112). They wanted to demonstrate that qualitative research had its own kind of rigour and that, through grounded theory, researchers could construct "abstract theoretical explanations of social processes" (Charmaz, 2014, 7). They began with these primary strategies: data collection and analysis take place simultaneously; codes and categories are constructed from the data; memo-writing is used to specify properties of categories and identify gaps; sampling is for the purpose of theory construction; and the literature review is done after developing independent analysis (8).

No overview of grounded theory is complete without mention of the schism of thought that occurred between Glaser and Strauss who eventually disagreed over approaches to coding and positioning of literature (MacLennan, 2012). Glaser's branch developed into a stricter version of grounded theory methodology (sometimes referred to as Orthodox GT), and Strauss went on to develop an 
objectivist approach that stressed constant comparisons between data and between data and theory (Strauss and Corbin, 1998).

Charmaz developed a third approach to grounded theory, constructivist, that emphasised the importance of context and that this in fact strengthened the resultant theory. Her view was to "assume a situated and embodied knowledge producer" rather than an "unbiased observer" (2009, 138-139). She argued, "Situating grounded theories in their social, historical, local, and interactional contexts strengthens them and supports making nuanced comparisons between data and among different studies. Subsequently these comparisons can result in more abstract—and, paradoxically, general—theories" $(2014,322)$. This situating of grounded theory is a primary reason it is the approach recommended for researching threshold concepts, although GT in its other forms has been used in LIS studies (Mansourian, 2006). In addition, in constructivist grounded theory, interview data are considered to be a reconstruction of an experience, rather than an experience itself. Eliciting the participants' views on what they found to be important about their experiences was used in the case illustration to situate the data. Another strength is that grounded theory demands rigorous analysis of the data and adherence to the iterative processes to achieve saturation and meet the high bar in the objectives of credibility, originality, resonance, and usefulness (Charmaz, 2014).

\subsubsection{Case illustration}

A case illustration that used grounded theory to explore threshold concepts in search expertise is presented to provide specific examples of GT research design and data gathering protocols within an LIS domain (Tucker, 2012). In brief, the study explored the learning experiences of professional searchers and highly proficient LIS graduate students (20 participants total). Its outcome was a grounded theory model of concepts, practices, and attributes, based on core themes that emerged from the data. The model is built upon the four concepts, essential to acquiring search expertise, that were found to have the characteristics of threshold concepts. The first three are: Information environment: the generation of information holistically is perceived and understood (publisher practices and the like); Information structures: content, index, and metadata structures are understood; Information vocabularies: fluency in search related to language, including natural language, controlled vocabularies, and finesse using proximity, truncation, and other language-based tools. The fourth threshold concept is Concept fusion, the integration of the other three threshold concepts and further characterised by having: visioning (knowing and anticipating the next moves); dancing (being light on one's 'search feet', ready to quickly change direction); and profound ontological shift. Participants described a "holistic information experience [that was] a 'magical thing', 'almost organic' or having 'synergy"' (Tucker, 2014, 247). In addition to the threshold concepts, themes from the study reached further findings related to search expertise, including praxes and traits of expert and professional searchers. 


\subsubsection{Data gathering and analysis}

The data gathering and analysis processes in grounded theory are not linear but overlapping; the activities of data collection, note taking, coding, and memoing take place simultaneously at certain points. As data collection and analysis move forward, further iterations of sampling take place "to safeguard against premature or uninformed interpretation" (Piantinida et al., 2004, 337). Theoretical saturation is achieved when no more new attributes or dimensions are emerging from the coding and comparison of codes and categories (Holton, 2010).

Data analysis is identifying "distinct units of meaning" (Coleman and O'Connor, 2007, 656), whether the source data is from interviews or researcher memos, and these are coded according to concepts they represent. These concepts are then clustered into categories which emerge into higher-level-or core-categories and themes that may begin to suggest theory. Memo-writing continues during the process of coding to "compare data, to explore ideas about the codes, and to direct further data-gathering" (Charmaz, 2014, 19).

Understanding the difference between categories and themes is important to the emergence of theory. Morse explained how to differentiate categories and themes thusly: "A category is a collection of similar data sorted into the same place...a theme, on the other hand, is a meaningful 'essence' that runs through the data. Just as a theme in opera occurs over and over again, sometimes in the foreground, sometimes in the background, and sometimes co-occurring with other tunes, so does the theme in our research" $(2008,927)$. In the threshold concepts case illustration, categories and themes were used according to Morse's definition: data were coded, then code clusters created to help in forming categories, but the themes that emerged ran like threads, at times woven across different categories, and they represented the more 'meaningful essence' of the data.

\subsubsection{Interviews and active tasks}

The study in the case illustration utilised semi-structured interviews and active tasks. For semi-structured interviews, the objective is to support participants in concretising their experiences. Creating participatory interviews contributes to this objective and has been described as a setting in which the interviewee is "more a participant in meaning-making than a conduit from which information is retrieved" (DiCicco-Bloom, 2006, 16). Kvale and Brinkman referred to interviewing as a craft and discussed the relationship between the participant and interviewer in this way:

The knowledge produced by [interview] research depends on the social relationship on interviewer and interviewee, which rest on the interviewer's ability to create a stage where the subject is free and safe to talk of private events recorded for later public use.

(Kvale and Brinkman, 2009, 16)

They also commented on the non-linear nature of the interview and the judgments of the interviewer in the process, adding that, "Interviewing rests on the practical skills and the personal judgments of the interviewer; it does not follow explicit steps of rule-governed methods" (17). 
The think-aloud (Lewis and Rieman, 1994; Ericsson and Simon, 1993) and talkafter protocols (Branch, 2000) were used to gather data on the learning of concepts and the skill development that take place while the participants are actively engaged in the search tasks. The two protocols provided concurrent and retrospective approaches to gathering information about the participant's experiences. Ericsson and Simon (1993) have argued that the closest connection between thinking and verbal reports is found when participants verbalize thoughts that arise during task completion. The method aims to extract the problem-solving and decision-making processes occurring in real time during the performance of the tasks. The talk-after protocol is appropriate for tapping into higher-order cognitive processes and was used in the post-search interviews. This provided the subjects the opportunity to reflect on what had happened during the search and also to re-visit questions from the pre-search interview.

Two potential confounding factors were taken into account in the design of the tasks: the participant's subject matter knowledge and the rapport the searcher has with the search engine. Because the impact of subject matter knowledge can be significant to search outcome for some topics (medical or legal, for example), this factor was minimised by having search tasks that required no knowledge of specialised vocabulary or subject matter.

\subsection{Research design elements}

In summary, using grounded theory to research threshold concepts is strongly supported by adopting several elements into the research design. These elements strengthen the method for eliciting evidence of core knowledge from professionals in the selected domain and the rigour of the data analysis stages. The constructivist approach to grounded theory (Charmaz, 2014) is recommended for its emphasis on situational research and because researcher and participant may work together toward 'meaning making' (Limberg and Alexandersson, 2009). The primary recommended elements of research design are:

- Gather data on learning experiences directly from the learners. Barradell expressed the concern for the lack of this element in much threshold concept research thusly, "Threshold concepts are defined by how disciplinary knowledge is learnt and experienced by students - yet more often than not, they are identified by academics who have long traversed the threshold" $(2013,267)$. In their commentary on information literacy research, Webber and Johnston point out that

The studies that have inspired ACRL's use of TCs [threshold concepts] have investigated the views of librarians teaching IL to learners of other subjects. This is different from identifying the threshold concepts of a discipline for learners aiming to think and practice in that discipline (the usual focus for threshold concepts).

(Webber and Johnston, 2016, 102)

- Also gather data from participants representing learners who have traversed the liminal space in the discipline. The case illustration reported in this article and the Decoding the Disciplines research both have demonstrated that rich 
data is to be gathered from faculty who teach in a given subject area and others with extensive relevant experience. One of the challenges of working with participants who are highly knowledgeable and experienced within the studied domain does mean they may be struggling to remember long-ago experiences and understandings that might today have new meaning or impact. As difficult as this may be, it is essential to the exploration of threshold concepts within a discipline.

- Arrange for participants to engage in tasks that are relevant to the learning experiences of interest. This element in the research design of "having participants actively engage in relevant tasks was effective in surfacing longago learning experiences, helping to overcome the obstacles of 'retracing the journey' (Cousin, 2006)" (Tucker, 2016, 103).

- Use semi-structured interviews and pose interview questions both pre- and post-task. Revisiting questions with different phrasings after the active tasks provides participants the opportunity to talk about experiences that may have been triggered during the tasks or may have become more fully recalled as a result of the task activities.

\section{Discussion}

As reported above, the study in the case illustration resulted in four threshold concepts being found for search expertise; its further findings included praxes and attributes of expert searchers (that were not threshold concepts) but, without which, we would not have the full portrait of what it means to be a professional searcher. This strongly suggested that the methodology could be applied to the discovery of not only threshold concepts, but also core knowledge, skills, and subject- and profession-guided practices. Or, in the situation of established competences - such as the ALA competences for librarianship, often used in adaptive forms in MLIS degree programs as program learning objectives (PLOs) - the protocols have potential to be used to evaluate learner experiences, helping to determine if the objectives have been reached, and if the competencies designed into the curriculum have been met. However, it is important to state that the nature of grounded theory precludes the prescriptive (pre-data gathering) setting of objectives for outcome and bringing in extensive literature review before data is gathered. Therefore, the recommendations are focused on the protocols and research design elements described, and need not be tied to grounded theory methodology itself. Other thematic analysis forms, such as template analysis (King, 1998), may be a suitable fit for specific research objectives.

\subsection{Conversation: threshold concepts and competences}

Both the conceptual frameworks and the case illustration's outcomes suggest that there is not only room but significant benefit to be had by including threshold concepts in conversations about core knowledge when establishing competences for an LIS domain and setting program learning objectives. Core competences may be (should be) difficult for students to master, but they may or may not be threshold concepts. The research further suggests an effective methodology and 
research design elements for exploring core knowledge in LIS domains and assessing how well it has been learned.

Many domains within LIS have clearly delineated competences for generic and subject knowledge, for example, in medical librarianship (MLA, 2016) and law librarianship (AALL, 2010). The American Library Association (ALA) has a set of competences and also maintains an extensive list of competency statements from other LIS professional organisations (ALA, n.d.). In addition, most MLIS degree programs have set competencies, often adapted from the ALA list (2009). In short, the idea of competences for laying out curriculum learning objectives and assessing graduates is solidly in place in the library and information science discipline and professions.

This conversation between threshold concepts and competences research demonstrates potential for what each conceptual framework brings to our understanding of what an LIS professional must traverse to fully join in the community of practice. It also raises questions to further that conversation: information literacy and expert searching have been studied and reported on here. Are there threshold concepts for collection management, information architecture, knowledge organisation, and other LIS domain areas? Might sages from these domains be participants in future studies that elicit their experiences on what truly matters for acquiring mastery in that domain? Are there threshold concepts for the LIS discipline as an entirety, core understandings that extend across all areas? How much of LIS domain knowledge is a moving target, and what parts are truly 'core' knowledge that is necessary to lifelong learning regardless the specific information pathway? Can rigorous analysis of data gathered help to identify trajectories for these paths?

\subsection{Affective dimensions of threshold learning}

Cousin has reminded educators to be cautious about the troublesome characteristic of threshold concept learning in how it surfaces in the learner's affective state:

I have explored some of the emotional issues that make learning troublesome, since it is important to temper the implicit suggestion in the idea of a threshold concept that the difficulty of its mastery inheres in the concept itself. While this is very often the case, we need to be aware that this difficulty cannot be abstracted from the learner or the social context.

(Cousin, 2006, 4)

She has noted that the affective dimension, particularly through evidence of anxiety, may provide one criterion for confirming that threshold learning experience is taking place. However, the affective dimensions of threshold learning experiences need not be investigated using qualitative methods alone. As an example, experimental research design is being applied to studying the impact of emotional state on searcher task performance and to exploring the affective dimension of stages in Kuhlthau's Information Search Process (ISP) model (Sarraf, 2015). Neuroscience methods can track the experiences of troublesomeness as a learner struggles to learn new material: "Brain scans now tell us that when someone makes a mistake in math and they struggle over 
something, synapses fire. When someone does not struggle and they get an answer correct nothing happens" (Boaler, as cited in Schwartz, 2015, n.p.). Boaler's research has demonstrated that, while two people can both arrive at the correct answer to a math problem, the one who struggles to do so has more trackable brain activity.

\subsection{Impacting curriculum}

This article has focused on discovery of threshold concepts through qualitative research methods. The next step is application of the research. A primary objective for threshold concepts studies is to apply the research to the design - or redesign - of curriculum such that it is guided by what the research has determined to be the threshold knowledge students need to acquire so they may move forward into a transformative domain of understanding. Impacting curriculum is at the core of threshold concepts. Cousin has stated, "the purpose of threshold concept research is to explore difficulties in the learning and teaching of subjects to support the curriculum design process" $(2008,201)$. As argued above, enlisting input from both faculty and students is essential during the discovery stages; it is likewise essential when implementing curriculum changes and evaluating them (Cousin, 2008). Course modifications will also be iterative as they are evaluated for effectiveness and the learning experiences of the students assessed to see if they have indeed acquired understanding of the threshold concepts that underlie the curriculum.

In some instances educators have predetermined threshold concepts and then initiated curriculum changes. For example, threshold concepts in physics and law were studied by Åkerlind, McKenzie, and Lupton. The researchers had established threshold concepts in physics and law, then focused their study on outcomes of both (1) the impact on the thinking and practice of the teachers; (2) the impact on students' learning (Åkerlind et al., 2011). Their findings bolstered the recommendation that multiple iterations of curriculum design are needed.

When threshold concepts are identified - using this term itself with informed caution (Barradell, 2013) - in LIS domains that reach a wide audience, most notably the ACRL frames for information literacy in higher education (2016), a flurry of activity to publish exercise workbooks and instructor support materials has been a consequence (Burkhardt, 2016). Another consequence is the heightened debate over educational venues where the frames, and the newly designed materials, may not be a fit for the learner demographic (Craven, 2016); yet another is the ongoing concern over whether or not the concepts in the Framework are in fact threshold concepts (Saracevic, 2014). Embedded in this concern is assessment and that the previous IL standards, which the frames are to supplant, allowed for more assessable learning outcomes. Further concerns about fall-out when concepts are treated as threshold concepts, but which are not, have been articulated by Webber and Johnston (2016) who cite further problems when concepts are detached from the learner's academic discipline. In the instance of the ACRL Framework, they cited two anomalies in how the IL threshold concepts were developed: "The first is in sidestepping the question of disciplinarity...the second anomaly is the ways in which TCs [threshold concepts] are fixed 
generically within the Framework, rather than acknowledging that IL is experienced differently within different subject disciplines" (102).

\subsection{Impacting practice}

Threshold concepts studies have as a primary purpose to provide guidance to designing curriculum such that it focuses on the core knowledge learners need to move toward becoming full members in a community of practice. As such, practitioners in the community can be impacted by lifelong learning that includes the revisiting of concepts and, through eliciting experiences from practitioners, more forward-thinking core competences can be framed.

Threshold concepts represent a relatively new theoretical construct that can be used to explore and identify essential concepts that work as transformative learning portals. To date, its application has been limited within LIS domains. LIS professionals are concerned about competencies that will endure and threshold concept theory provides a framework for studying core knowledge that is independent of shifting technologies. Extending this construct may provide further insights for other practice areas within library and information science.

\section{Conclusion}

This article has reviewed a range of methodologies that have been brought to threshold concept research within library and information science domains. It has demonstrated that constructivist grounded theory provides specific benefits for discovery of threshold concepts, and has set forth ways to implement and strengthen the methodology for this purpose through identifiable elements in the research design. Further, the discussion has shown that these research design elements may be extended to the discovery of other core knowledge- knowledge that may not have the characteristics of threshold concepts but which is nevertheless essential to an LIS domain - and this may help with both delineation and assessment of competences for the LIS professions. The methodologies and protocols discussed, with threshold concepts as the theoretical framework, can impact LIS practice through enlightenment of core competences, clearer framing of areas where subject domain knowledge must be factored in, as well as ways of designing curriculum to support the learning of concepts and competences.

\section{References}

Åkerlind, G., McKenzie, J., and Lupton, M. (2011) Final report: a threshold concepts focus to curriculum design: supporting student learning through application of variation theory. URL: http://eprints.qut.edu.au/69603/ [accessed 15.02.2017]

Åkerlind, G., McKenzie, J., and Lupton, M. (2014) The potential of combining phenomenography, variation theory, and threshold concepts to inform curriculum design in higher education. In: Tight, M. and Huisman, J. (eds.) Theory \& method in higher education II, vol. 10. Bingley, UK: Emerald Group Publishing. 227-247.

American Association of Law Librarians (AALL) (2010) Competencies of law librarianship. URL: http://www.aallnet.org/mm/LeadershipGovernance/policies/PublicPolicies/competencies.html [accessed 10.02.2017] 
American Library Association (ALA) (2009) Core competences of librarianship. URL: http://www.ala.org/educationcareers/files/careers/corecomp/corecompetences/fina lcorecompstat09.pdf [accessed 15.02.2017]

American Library Association (ALA) (n.d.) Knowledge and competencies statements developed by relevant professional organizations. URL:

http://www.ala.org/educationcareers/careers/corecomp/corecompspecial/knowled gecompetencies [accessed 15.02.2017]

Association of College and Research Libraries (ACRL) (2015) Framework for information literacy for higher education. URL:

http://www.ala.org/acrl/standards/ilframework [accessed 15.02.2017]

Barradell, S. (2013) The identification of threshold concepts: a review of theoretical complexities and methodological challenges, Higher Education, 65(2), 265-276.

Barradell, S. and Peseta, T. (2016) Promise and challenge of identifying threshold concepts: a cautionary account of using transactional curriculum inquiry, Journal of Further and Higher Education, 40(2), 262-275.

Bawden, D. (2012) On the gaining of understanding: syntheses, themes and information analysis, Library and Information Research, 36(112), 147-162.

Benedetti, A., Jackson, J., and Luo, L. (2017, forthcoming). Vignettes: implications for LIS research, College \& Research Libraries.

Blackmore, M. (2010) Student engagement with information: applying a threshold concept approach to information literacy development. Proceedings of the Third Biennial Threshold Concepts Symposium. Sydney, Australia, 1-2 July 2010.

Boustedt, J., Eckerdal, A., McCartney, R., Moström, J.E., Ratcliffe, M., Sanders, K. and Zander, C. (2007) Threshold concepts in computer science: do they exist and are they useful? ACM SIGCSE Bulletin, 39, 504-508.

Branch, J.L. (2000) Investigating the information-seeking processes of adolescents: the value of using think alouds and think afters, Library \& Information Science Research, 22(4), 371-392.

Braun, E. and Mishra, S. (2016) Method for assessing competences in higher education: A comparative review. In: Tight, M. and Huisman, J. (eds.) Theory \& method in higher education, vol. 2. Bingley, UK: Emerald Group Publishing. 4768.

Burkholder, J. (2011) Decoding the discipline of music history for our students, Journal of Music History Pedagogy, 1(2), 93-111.

Charmaz, K. (2009) Shifting the grounds: constructivist grounded theory methods. In: Morse, J.M., Stern, P.N., Corbin, J., Bowers, B., Charmaz, K., and Clarke, A.E. (eds.) Developing grounded theory: the second generation. Walnut Creek, CA: Left Coast Press. 127-193.

Charmaz, K. (2014) Constructing grounded theory. 2nd ed. Thousand Oaks, CA: Sage Publications. 
Coleman, G. and O'Connor, R. (2007) Using grounded theory to understand software process improvement. Information and Software Technology, 49, 654667.

Cousin, G. (2006) Introduction to threshold concepts, Planet, 17, 4-5.

Cousin, G. (2008) Researching learning in higher education: an introduction to contemporary methods and approaches. New York: Routledge.

Cousin, G. (2010) Neither teacher-centred nor student-centred: threshold concepts and research partnerships, Journal of Learning Development in Higher Education, 2, 1-9.

Craven, H. (2016) ACRL and community college libraries: we've been framed, Community \& Junior College Libraries, 22(1), 3-5.

Davies, P. and Mangan, J. (2005). Recognising threshold concepts: an exploration of different methods. European Association in Learning and Instruction Conference (EARLI), 23-27 August 2005, Nicosia, Cyprus.

Díaz, A., Middendorf, J.K., Pace, D., and Shopkow, L. (2008) The history learning project: adepartment 'decodes' its students, Journal of American History, 94(4), 1211-1224.

Díaz, A. and Pace, D. (2012). Introduction to decoding the disciplines:

preconference Workshop. Threshold Concepts $4^{\text {th }}$ Biennial Conference, 27 June 2012, Dublin, Ireland.

DiCicco-Bloom, B. (2006) The qualitative research interview, Medical Education, 40(4), 314-321.

Dunne, C. (2011) The place of the literature review in grounded theory research, International Journal Social Research Methodology, 14(2), 111-124.

Ericsson, K. and Simon, H. (1993) Protocol analysis: verbal reports as data. 2nd ed. Cambridge, MA: MIT Press.

European Commission (EC) (2015) European Higher Education Area: Bologna Process Implementation Report. URL:

eacea.ec.europa.eu/education/eurydice/documents/thematic_reports/182EN.pdf [accessed 18.02.2017]

Flanagan, M. T. (2017) Threshold concept bibliography: statistics. URL: http://www.ee.ucl.ac.uk/ mflanaga/thresholds_stats.html [accessed: 19.02.2017]

Glaser, B.G. and Strauss, A.L. (1967) The discovery of grounded theory. New York: de Gruyter.

Glenn, D. (2009) A teaching experiment shows students how to grasp big concepts, Chronicle of Higher Education, 56(13), A1-A10.

Gross, M. (2005) The impact of low-level skills on information-seeking behavior: implications of competency theory for research and practice, Reference \& User Services Quarterly, 45(2), 155-162. 
Holton, J.A. (2010) The coding process and its challenges. In: Bryant, A. and Charmaz, K. (eds.) The Sage handbook of grounded theory. Thousand Oaks, CA: Sage Publications. 265-289.

Jacobs, C. (2014) Methodological meditations on producing rich narrative data. In: Tight, M. and Huisman, J. (eds.) International perspectives on higher education research, vol. 10. Bingley, UK: Emerald Group Publishing. 63-81.

King, N. (1998) Template analysis. In: Symon, G. and Cassell, C. (eds.) Qualitative methods and analysis in organizational research: a practical guide. Thousand Oaks, CA: Sage Publications. 118-134.

Kvale, S. and Brinkmann, S. (2009) InterViews: learning the craft of qualitative research interviewing. 2nd ed. London: Sage Publications.

Land, R., Meyer, J.H.F., and Baillie, C. (2010) Preface: threshold concepts and transformational learning. In: Meyer, J.H.F., Land, R., and Baillie, C. (eds.) Threshold concepts and transformational learning. Rotterdam: Sense Publishers. ix-xlii.

Lewis, C. and Rieman, J. (1994) The thinking aloud method. In: Lewis, C. and Rieman, J. (eds.), Task-centered user interface design: A practical introduction. Section 5.5. URL: http://hcibib.org/tcuid/ [accessed 15.02.2017]

Limberg, L. and Alexandersson, M. (2009) Learning and information seeking. In: Bates, M.J. and Maack, M.N. (eds.) ELIS, Encyclopedia of Library and Information Sciences. 3rd ed. Boca Raton, FL: CRC Press.

Lozano, J. F., Boni, A., Peris, J., and Hueso, A. (2012) Competencies in higher education: a critical analysis from the capabilities approach, Journal of Philosophy of Education, 46(1), 132-147.

MacLennan, A. (2012) Immersed in cyberspace : An evaluation of a grounded theory approach to a study of user preferences, Library and Information Research, 36(112), 55-71.

Mansourian, Y. (2006) Adoption of grounded theory in LIS research, New Library World, 107(9), 386-402.

Medical Library Association (MLA) (2016). MLA's competencies for lifelong learning and professional success. URL: http://www.mlanet.org/p/cm/ld/fid=39 [accessed 18.02.2017]

Meyer, J.H.F. and Land, R. (2003). Threshold concepts and troublesome knowledge: linkages to ways of thinking and practising within the disciplines. In: Rust, C. (ed.) Improving student learning: ten years on. Oxford: OCSLD. 1-16.

Meyer, J.H.F. and Land, R. (2005) Threshold concepts and troublesome knowledge (2): epistemological considerations and a conceptual framework for teaching and learning, Higher Education, 49(3), 373-388.

Mezirow, J. (2003) Transformative learning as discourse, Journal of Transformative Education, 1(1), 58-63.

Morse, J.M. (2008) Confusing categories and themes, Qualitative Health Research, 18(6), 727-728. 
Mulder, M. (2015) Professional competence in context: A conceptual study, Proceedings of the American Educational Research Association, April 2015, Chicago, IL. URL: http://www.aera.net/Publications/Online-PaperRepository/AERA-Online-Paper-Repository [accessed 08.02.2017]

Pace, D. and Middendorf, J.K. (2004) Decoding the disciplines: Helping students learn disciplinary ways of thinking. San Francisco: Jossey-Bass.

Perkins, D. (2006) Constructivism and troublesome knowledge. In: Meyer, J.H.F. and Land, R. (eds.), Overcoming barriers to student understanding: Threshold concepts and troublesome knowledge. New York: Routledge. 33-47.

Perkins, D. (2010) Foreword. In: Meyer, J.H.F., Land, R., and Baillie, C. (eds.), Threshold concepts and transformational learning. Rotterdam: Sense Publishers. xliii-xlv.

Piantinida, M., Tananis, C.A. and Grubs, R.E. (2004) Generating grounded theory of/for educational practice: the journey of three epistemorphs, International Journal of Qualitative Studies in Education, 17(3), 325-346.

Quinlan, K. M., Male, S. A., Baillie, C. A., Stamboulis, A., Fill, J., and Jaffer, Z. (2013) Methodological challenges in researching threshold concepts: a comparative analysis of three projects, Higher Education, 66(5), 585-601.

Rowbottom, D.P. (2007) Demystifying threshold concepts, Journal of Philosophy of Education, 41(2), 263-270.

Saracevic, T. (2014) Information literacy in the United States: contemporary transformations and controversies. In: Kurbanoglu, S. et al. (eds.), Information literacy: lifelong learning and digital citizenship in the 21 st century. Dordrecht, The Netherlands: Springer Verlag. 19-30.

Sarraf. N. (2015) Mapping the affective brain activities of the Information Search Process Model. https://nilosarraf.com/2015/10/22/mapping-eeg-of-isp-model/ [accessed 15.02.2017]

Schwartz, K. 30 Nov 2015. Not a math person: how to remove obstacles to learning math. KQED News [online]. URL:

https://ww2.kqed.org/mindshift/2015/11/30/not-a-math-person-how-to-removeobstacles-to-learning-math/ [accessed 15.02.2017]

Shinners-Kennedy, D. (2016) How not to identify threshold concepts. In: Land, R., Meyer, J.H.F., and Flanagan, M.T. (eds.), Threshold concepts in practice. Rotterdam: Sense Publishers. 253-267.

Soules, A. (2012) Is it really on the Web and what does that mean for instruction and reference? Qualitative and Quantitative Methods in Libraries (QQML), 2 , 177-183.

Strauss, A.L. and Corbin, J. (1998) Basics of qualitative research: grounded theory procedures and techniques. 2nd ed. London: Sage Publications.

Tight, M. (2014) Theory development and application in higher education research: the case of threshold concepts. In: Tight, M. and Huisman, J. (eds.) 
Theory \& method in higher education research II. Bingley, UK: Emerald Group Publishing. 249-266.

Townsend, L., Brunetti, K., and Hofer, A.R. (2011) Threshold concepts and information literacy, Libraries \& the Academy, 11(3), 853-869.

Townsend, L., Hofer, A. R., Lin Hanick, S., and Brunetti, K. (2016) Identifying threshold concepts for information literacy: A Delphi study, Communications in Information Literacy, 10(1), 23-49.

Tucker, V.M. (2012) Acquiring search expertise: learning experiences and threshold concepts. Ph.D. dissertation, Queensland University of Technology, Brisbane, Australia. URL: http://eprints.qut.edu.au/63652/ [accessed 15.02.2017]

Tucker, V.M. (2014) The expert searcher's experience of information. In: Bruce, C.S., Davis, K., Hughes, H., Partridge, H., and Stoodley, I. (eds.), Information experience: approaches to theory and practice. Bingley, UK: Emerald Group Publishing. 239-255.

Tucker, V.M. (2016) Learning experiences and the liminality of expertise. In: Land, R., Meyer, J.H.F., and Flanagan, M.T. (eds.), Threshold concepts in practice, (pp.. Rotterdam: Sense Publishers. 93-106.

Tucker, V.M., Bruce, C., and Edwards, S.L. (2016) Using grounded theory to discover threshold concepts in transformative learning experiences. In: Tight, M. and Huisman, J. (eds.), Theory and method in higher education, vol. 2, (pp.). Bingley, UK: Emerald Group Publishing. 23-46.

Tucker, V.M., Weedman, J., Bruce, C.S., and Edwards, S.L. (2014) Learning portals: Analyzing threshold concept theory for LIS education, Journal of Education for Library \& Information Science, 55(2), 150-165.

Turner, V. (1969) The ritual process. Chicago: Aldine.

UNESCO. (n.d.) Education for the $21^{\text {st }}$ century: competencies. URL: http://www.unesco.org/new/en/education/themes/strengthening-educationsystems/quality-framework/desired-outcomes/competencies/ [accessed 15.02.2017]

United States Department of Education. (n.d.) Competency-based learning. URL: https://www.ed.gov/oii-news/competency-based-learning-or-personalizedlearning [accessed 15.02.2017]

Walker, G. (2013) A cognitive approach to threshold concepts, Higher Education, 65, 247-263.

Webber, S. and Johnston, B. (2016) Information literacy, threshold concepts, and disciplinarity. Fourth European Conference on Information Literacy (ECIL), Prague, Czech Republic.

Yukawa, J. (2015) Preparing for complexity and wicked problems through transformational learning approaches, Journal of Education for Library \& Information Science, 56(2), 158-168.

Zwaneveld, B., Perrenet, J. and Bloo, R. (2016) Discussion of methods for threshold research and an application in computer science. In: Land, R., Meyer, 
J.H.F., and Flanagan, M.T. (eds.), Threshold concepts in practice. Rotterdam: Sense Publishers. 269-284.

\section{Open access and copyright}

Library and Information Research is an open access journal. A freely available copy of this paper may be downloaded from the journal's website: http://www.cilipjournals.org.uk/

Copyright and associated moral rights in works published in Library and Information Research are retained by the author(s) but this paper may be used freely, with proper attribution, in educational and other non-commercial settings. 